Submitted: 18.02.2016.

Accepted for publication: 03.08.2016.

\title{
Reformed gatekeeping
}

\author{
François Heinderyckx ${ }^{1}$ \\ Université libre de Bruxelles (ULB), Belgium \\ Tim P. Vos ${ }^{2}$ \\ University of Missouri, USA
}

doi: $10.5937 /$ comman11-10306

Abstract: This essay explores the state of gatekeeping theory at present. We discuss whether gatekeeping theory has a future, how gatekeeping - as it has evolved - still offers theoretical and explanatory value, and how gatekeeping must be reformed to maintain its worth and relevance. The notion is approached from its purpose, nature, temporality, agents and context. The article argues that gatekeeping theory will remain relevant pending a process of reform that must accompany that of journalism and news media.

Keywords: gatekeeping, news selection, journalism, news media, digital age.

\section{Introduction}

Gatekeeping theory came together to formalize some of the core processes involved in journalism and news reporting. Because the news industry is endemically in flux, and because it is currently undergoing systemic transformations within the context of the development of digital technologies, all theoretical frames in this area come under considerable pressure and challenge. Pre-digital-era theories have to be adapted and prove their renewed relevance, or be abandoned in obsolescence. Gatekeeping theory has been challenged long before the current turmoil; in fact it was challenged almost from the start. It has been tweaked, adapted, expanded, repurposed in various ways to improve it and

\footnotetext{
1 Contact with author: fheinder@ulb.ac.be.

2 Contact with author: vost@missouri.edu.
} 
to adjust to the evolution of the objects to which it applies. Yet, the magnitude of the changes triggered by the digital transformations of media and communication introduces a discontinuity that could make gatekeeping theory lose part or all of its relevance. To remain in the game, gatekeeping theory needs to be revamped.

This essay explores the state of gatekeeping theory at present. We explore whether gatekeeping theory has a future, how gatekeeping - as it has evolved - still offers theoretical and explanatory value, and how gatekeeping must be reformed to maintain its worth.

\section{Requiem for Gatekeeping in a Digital Age?}

The very idea of gatekeeping came about in the old media world - a time when news products were few and hard to access, when editors made choices and audiences simply lived quietly with those choices, when the tools for creating the news were limited, and when space for news was at a premium. In the world of new, converged media where news is accessible via the internet, the tools for news creation have vastly expanded, the space for news content has grown massively, audiences are a source of constant and immediate feedback, and audiences are more likely to choose news with little regard for who has published it - gatekeeping theory might just have run its course.

It should come as little surprise that scholars and critics have challenged the idea of gatekeeping and questioned its relevance in the digital age (see e.g., Pearson \& Kosicki, 2016). Gatekeeping scholarship in its original form sought to explain little more than how news got selected for publication (White, 1950). The question of what news actually made it to the public was largely ignored because it was assumed that legacy news media output largely constituted the news environment (Shoemaker \& Vos, 2009). In this scenario, legacy media were the gatekeepers and the relevance of gatekeeping would rise or fall with the vitality of the legacy media. In the early decades of the twenty-first century, legacy media are in trouble and new channels of information distribution are sapping them of their control of the news and information environment.

Gatekeeping is questioned then because legacy media - established printed newspapers and TV network news broadcasts - are seen as fading institutions. While that is certainly believable, it begs the question of what it means that an institution is fading. While fading is stated in the present tense, it is also clear 
that legacy media have not yet faded to irrelevance. Quite the opposite. Much of the news that circulates through digital media originates with legacy media. But more importantly, the observation comes with an implicit assumption or projection about the future - that we will arrive at a digital age in which legacy media will be replaced by some kind of new, digital replacement. However, as researchers, we do our work in an empirical world. The digitization of news is happening. But, it is also premature to say that a new digital age has eclipsed the legacy media, particularly when it comes to the production of news. Lessons should be learned from the failed predictions of the demise of the paper book, which were supposed to be taken over by the so much more efficient e-books. Since models and theories purport to describe and explain the empirical world, we can only account for the here and now. In the meantime, we have a world in transition - a world in which the old and the new co-exist (Pearson \& Kosicki, 2016). The end may yet come for gatekeeping. But making that conclusion now would be premature. What we can say is that gatekeeping is in transition. This too unavoidably says something about the future; however, it remains reasonably agnostic about the kind of future that awaits gatekeeping.

So, before anyone pronounces the death of gatekeeping theory, we owe the patient a close examination. In fact, a first step would be to make sure we are even examining the right patient; or put more simply, we need to be sure what is meant by gatekeeping before we mark its passing. Indeed, gatekeeping has had a variety of meanings and these must be sorted out: There is the concept of gatekeeping, a gatekeeping function, a gatekeeping role, a gatekeeping model, and gatekeeping theory.

The concept of gatekeeping has largely referred to how information circulates or does not circulate (Lewin, 1951). Gatekeeping is a means for accounting for the reality that not all information is equally available to all persons. The gatekeeping function refers to those realities of the social, physical, and digital world that inhibit or advance the flow of information. These factors that inhibit or advance the flow of information can be independent of the agency or intention of any particular actors in the information environment. A news organization, for example, can perform a gatekeeping function whereby some information becomes news and some does not. However, we can also talk about a gatekeeping role. This refers to a normative role whereby certain actors in the information environment see it as their duty or responsibility to pass 
along some information and not other forms or kinds of information (Janowitz, 1975). This role flows from an understanding of the role that news media should play in society if certain pro-social values are to be realized. Granted, the role can also be an expression of marketing considerations - seeking to target a particular market demographic.

Indeed, it is these realities of the social, physical, and digital world that have led scholars to seek to understand and explain the processes by which "tips, hunches, and bits of information ... get turned into news and how that news is framed, emphasized, placed, and promoted" and how it reaches a reader, listener, or viewer (Vos, 2015: 4). Scholars have sought to produce gatekeeping models that plot the channels of information distribution and identify the aspects and intentions of the social, physical, and digital world that shape the flow of information (Shoemaker, 1991; White, 1950). These models call researchers' attention to factors that, at certain times and in certain places, plausibly account for how certain kinds of information might make it to the public and certain kinds of information might not.

Gatekeeping theory, meanwhile, goes beyond the factors identified in a gatekeeping model and posits enduring features of the social, physical, and digital worlds - things such as socialization and social institutions and norms and enduring human characteristics - things like cognitive and rational capacities - to offer explanations for a range of enduring patterns of news production and reception (Shoemaker \& Vos, 2009). Thus, gatekeeping theory is culturally specific, but also identifies features that account for human actions across time and place. It is gatekeeping theory then that is the focus of our attention here. We will argue that gatekeeping theory retains relevance, but that it must be revisited and revitalized for the digital age.

\section{Relevance for Gatekeeping in a Digital Age}

So, why is gatekeeping theory worth keeping? The succinct answer is because the phenomena it describes and explains are still relevant. If the concept of gatekeeping accounts for how information circulates or does not circulate and why all information is not equally available to all persons, then it should be clear that gatekeeping addresses phenomena that still very much exist. Since circulation patterns of information are not simply random and since a variety of 
institutions, organizations, individuals, and technologies continue to perform a gatekeeping function, gatekeeping theory has not yet exhausted its usefulness.

A common criticism of gatekeeping is that new digital technologies produce substantially new production and distribution capacities, such that information scarcity is no longer as relevant as it once was. However, these claims are being made at the very time, particularly in the U.S., when the number of actors who construct news is shrinking. Granted, the numbers of actors who distribute information have grown more numerous - citizens share information via social media and websites and aggregators represent an enormous expansion of news and information distribution. But evidence is in short supply that would show that the amount and nature of the actual news that reaches the public have radically changed. Audiences also have a limited capacity to attend to news, suggesting that the marketplace for news is more finite than pronouncements about digital capacity typically acknowledge.

Meanwhile, news organizations continue to embrace a gatekeeping role by deciding how they want to use their limited resources to create an identity or brand (Tandoc, 2014; Tandoc \& Vos, 2015). While legacy media, for example, face greater and greater competition, the response has been to become more selective, not less, about what gets published. News organizations - and aggregators - continue to make choices and those choices - because they limit the news available to the public - have consequences for the public and institutional decision makers (Starkman, 2014). And this is why gatekeeping models and gatekeeping theory are still vitally important - they allow us to address important questions that merit public attention and debate. As posed elsewhere: "given the range and variety of journalists and news organizations engaged in decision-making, how is it that those journalists and news organizations, when confronted by a complex phenomenon, are capable of producing such a narrow range of news messages?" (Vos, 2015, p. 7). From perspectives that see news news that is accurate, nuanced, and empowering - as essential to enlightened self-governance (Christians, Glasser, McQuail, Nordenstreng, \& White, 2009), anything that shapes or limits the news environment bears scrutiny.

As mentioned at the outset many journalists embrace a normative gatekeeping role. They recognize a moral obligation to limit certain kinds of news - for example, sensationalism and public relations disguised as news - and to emphasize news of significance - for example, news that exposes public corruption or 
threats to public safety or health. Other journalists, of course, embrace other obligations, such as giving audiences what they want and hopefully raising revenues in the process (Bourdieu, 2005). Critical theorists have examined the news environment precisely because they identify the consequences of those gatekeeping choices as critical to public justice and public health. Indeed, if a public corruption is largely ignored or minimized within the news environment, if a serious threat to the public health receives only limited local exposure, how could such normative failings be explained? While critical theory might point to broad explanatory frameworks, gatekeeping theory potentially explains how such failings can come about (Schudson, 2012; Shoemaker \& Vos, 2009).

Take, for example, a recent debate among U.S. journalists about a general failure to cover a major public health crisis in the upper midwestern city of Flint, Michigan. The episode is a useful lens through which to examine the state of gatekeeping and gatekeeping theory and illustrative of some of the points raised thus far and points to be elaborated on below. Media critics (e.g., Warren, 2016), including the public editor of the New York Times (Sullivan, 2016), asked how it could be that major news outlets could give such scant attention to lead-poisoning from the public water supply of a sizeable American city. The Times' public editor put the question to the paper's executive deputy editor. What ensued was a discussion about news judgment and editorial decisions, a framework that focused on an individual level of analysis. Other critics (e.g., Moore, 2016), meanwhile, pointed to governmental inaction and the dearth of news about the contamination and suggested the answer could be found in the class and race of the city's inhabitants. What does the episode help us to see and explore?

First, gatekeeping theory has been questioned on the grounds that the gatekeeping function has lost most of its significance. The rapid growth in news portals and the predominance of social media was supposed to make any attempt at gatekeeping a pointless exercise. Legacy media might hold back on a story, but Twitter, Facebook, or other social media would add so many open gates to the news field that information could not be contained. Yet, the lead poisoning story received limited public traction in Michigan and only passing attention outside the state. Policymakers inside and outside the state gave the public health threat essentially no public attention. If the gatekeeping phenomenon is one of keeping information from flowing freely, the phenomenon still seemed to be in evidence in the Flint water case and hence merits our theorizing. 
Second, the story of Flint's water quality did eventually become a significant national news story, with the accompanying outrage directed at public officials who had had a hand in creating and concealing the crisis. But, it was the presence of national, legacy media that eventually amplified the story and brought about an examination of policy failures (Hiner, 2016). As discussed later, the legacy media had the cultural capital to place the crisis on the public agenda, illustrating that the qualities of the gatekeeper are not immaterial. In other words, lots of open gates in local media and, presumably, in social media made almost no impact compared to the open gates of a national cable network, a national TV network, and a national newspaper.

Third, when it comes to actually explaining how the story could be held back for so long, gatekeeping theory provides a useful set of conceptual tools. Gatekeeping scholarship has long identified the role of government and officials sources as the keepers of information gates. The fact that government sources in Flint repeatedly affirmed that the drinking water was safe, and the fact that journalists repeated these claims, kept the story in check. News routines that rely on and privilege elite sources regularly structure the news environment and did so in the Flint case as well. Local news organizations - the most likely to uncover the crisis - were under staffed and struggled to put sufficient resources into the story. Organizational characteristics have long shaped the news environment, as they did in this case. News organizations are not isolated from powerful institutional narratives, such as belief in a watchdog role, and Flint media began to put investigative resources into the story. Meanwhile, the readership of the local newspaper did not show widespread interest in the story, clicking instead in far greater numbers on stories about a state sports rivalry and routine weather (Hiner, 2016). Thus, audience cues also downplayed the story. And social system characteristics, such as the marginalized racial and class characteristics of those most affected by the crisis, presumably fed into audience disinterest. Thus, each of the factors mentioned here are well established in the gatekeeping scholarship as factors that structure the news environment, suggesting the utility of gatekeeping theory in this important case and cases like it.

\section{Reform for Gatekeeping in a Digital Age}

Gatekeeping scholarship, as noted above, has reformulated the concept of gatekeeping at various times. The early reformulations were less a matter of adjusting to shifting news realities than to shifting theoretical complexity. White's 
(1950) version of gatekeeping focused on news selection. Later versions sought to explain how information was selected, shaped and framed (Reese \& Ballinger, 2001). White's version located explanation at an individual level, conceptualizing gatekeeping as a journalist's decision making. Subsequent scholars soon began to point to structure factors that influenced individual decision making (Gieber, 1956; Pool \& Shulman, 1959). Shoemaker (1991) would systematize these factors into a single gatekeeping model and thereby create a second life for gatekeeping theory.

Revisiting gatekeeping theory anew begins with testing whether or not its epistemic core remains relevant. From the broadest sense of gatekeeping as "the process of culling and crafting countless bits of information into the limited number of messages that reach people each day" (Shoemaker \& Vos, 2009, p. 1 ), there is no doubt that gatekeeping will remain relevant for as long as news will be processed and disseminated to an audience. Whether or not that process is in the hands of identifiable gatekeepers and what the nature of those might be is much more debatable. Whether or not the original metaphor of items flowing through channels punctuated by a succession of gates still adequately models the way events become news must also be closely examined. If all this appears to remain at least partially relevant, then what we think we know about gatekeeping must be updated to digital-media-grade realities.

Gatekeeping, in the broad sense, has outgrown its original metaphor into a complex mesh of concepts and theories that must inevitably be broken down into smaller conceptual units to be upgraded to the current realities of the digital age. Breaking down complex mechanisms into smaller, manageable parts, is how modern science has dealt with complexity since René Descartes and later Isaac Newton introduced reductionism in the 17th century. Reductionism is a risky route where the smaller parts are closely intertwined to the point where each of those parts cannot be properly understood when considered isolated from the others. To face complexity while avoiding the drawbacks of reductionism, an alternative strategy consists in examining the complex object from different angles, using different perspectives. By doing so, we preserve a somewhat holistic view which divides the object not in a succession of steps, but rather in several layers cutting across the overall process.

Gatekeeping has been sliced into five theoretical levels by Shoemaker and her colleagues (Shoemaker, 1991; Shoemaker \& Vos, 2009; Shoemaker, Vos, \& 
Reese, 2008): individual, communication routines, organizational, social institution, and social system. Each of these levels can host an in-depth analysis of gatekeeping overall, without isolating one step or another, though some levels might be of particular importance for specific aspects of the process. To understand how gatekeeping has evolved over the course of the digital transition, we can also proceed by examining the alteration in the purpose of gatekeeping, its very nature, its temporality, its agents, and its context (Heinderyckx, 2015).

Purpose of Gatekeeping. The purpose of gatekeeping has enlarged beyond mere editorial space management given that digital media have considerably lightened the strict limits constraining print, radio and television news outlets. Digital outlets proudly did away with limited editorial space, which could lead to believe that gatekeeping loses its importance accordingly (Bruns, 2011). Yet producing content requires human and technological means, both of which come at a considerable cost. In a context where financial resources are scarce and media struggle to develop new business models, news media have to make choices as much as ever. Technology does make space for ever more content, but the limited resources available to produce content limit news production. Yet, news media feel compelled to fit in the culture of abundance that is associated with digital outlets (Curran, 2010). Because 'the goat must be fed' (Stencel, Adair, \& Kamalakanthan, 2014), a range of new practices have developed to curate content from around the web to cram the digital operations of media outlets, thus opening up a new purpose for gatekeeping.

Yet, the attention span of individuals remains stable and very limited. The abundance of content combined with sophisticated digital technologies create high expectations for a kind of individualized gatekeeping. Although the 'Daily Me' conceptualized by Nicholas Negroponte (1995) over twenty years ago hasn't yet materialized, the tools available to curate and filter content will at some point empower individuals to become their own gatekeeper, though a second-degree gatekeeper given that the supply of content to which they have access functions with its own gatekeeping mechanisms. An entire industry of start-ups is constantly fiddling with various ways to process and repurpose content so that media might meet these expectations of personalized content. By trial and error, they stretch and manhandle gatekeeping in ways that become a significant factor in shaping the evolution of gatekeeping. 
As suggested above, legacy media no longer have a monopoly when it comes to determining the scope and content of the news environment. Gatekeepers no longer presume that their role is to shape the news environment, but to contribute to it. Hence, in some cases, the purpose has evolved into getting a news organization's share of customers and revenue (Tandoc, 2014). Put more generously, some gatekeepers use their gatekeeping choices to distinguish themselves from the flood of potential competitors and thereby develop a brand identity (Phillips, 2015). Gatekeeping's purpose is to market the gatekeeping organization (Tandoc \& Vos, 2015). Thus, gatekeeping must be theorized not just as factors shaping the news environment - although this remains highly relevant - but also factors that shape gatekeepers' brands and identities.

Nature of Gatekeeping. The very nature of gatekeeping is changing. From a process of selection and production determined by the presumed relevance of certain events for a specific audience (White, 1950), gatekeeping now also includes the various ways by which media outlets must tap into a much wider range of channels (not just news sources) to dazzle the audience with the diversity, quantity and quick turnover of content. The main driver of this extended gatekeeping is to attract traffic (clickbait) and stimulate recommendation (buzz).

The exponential mass of content housed within the digital media system also gave birth to a string of automated technologies which we have come to believe are the only way to deal with content abundance. At the core of these technologies, mysterious (and secret) algorithms are said to be able to cater to our every need in content management (Anderson, 2013). Whatever the need or the expectation, algorithmic magic will provide a solution. As a result, various forms of algorithmic gatekeeping have become part and parcel of the news media industry. Because the original gatekeepers were essentially human operators (reporters and editors), gatekeeping theory has always struggled to unpack gatekeeping from within the complexity of human cognition and decision making. The online search selection behavior of readers and viewers of news is now also part of what is captured by algorithms, thereby making individuals into contributors to their own news environment. With the algorithmification of gatekeeping, we must now wonder how the process can be modeled into mathematical equations and how this will affect the overall balance of news production and dissemination. Algorithms are trade secrets and they have become 
something of a myth associated with a certain degree of magic and fascination. Yet, the same algorithms are still developed by human operators whose views on gatekeeping are still key and of which the application or online service will only be an approximate modeling in the form of an algorithm.

Gatekeeping in the digital age has considerably shifted from a logic of relevance (Harcup \& O'Neill, 2001) towards one of popularity. The primary unit of newsworthiness is increasingly how popular a story will be among digital users, how many clicks, likes, retweets or whatever else measure of digital impact may be considered (Tandoc, 2014). What matters overall is whether a story will attract attention (and traffic) and how it can be narrated to enhance its potential. Gatekeeping becomes increasingly driven by the expected, then the measured effect it will have in attracting a sizeable audience, preferably one that is of interest to advertisers (Tandoc, 2015).

While early theories of gatekeeping stopped with explaining why news turns out the way it does, recent theorizing has extended the objects of study to account for the kind of news that reaches an audience (Vos, 2015). This requires attention to channels of distribution, including social media, aggregation, and traditional media channels (Thorson \& Wells, 2015). Gatekeeping has sometimes been linked to media's agenda-setting function, but this relationship has become more critical. In an information-abundant environment, only some news maintains a place on the public agenda beyond a 24-hour news cycle. Gatekeeping theory must now account for this phenomenon as well.

As attention turns to alternative channels of news distribution, attention must also turn to the nature of those gatekeeping channels. While all these channels have largely been seen in the same theoretical terms, they may require careful theoretical distinctions. The Flint water-poisoning story suggests why this might need to be the case. The story found open gates. However, those gates did not open into channels that led to anything like a significant audience. The channels did not have the capacity or cultural capital to move the public agenda. It took the open gates of the national, legacy media for the issue to reach a critical mass.

Temporality of Gatekeeping. The temporality of gatekeeping was also altered by the fast pace imposed upon news media by the continuous flow of news that has overwhelmed the news cycles of the traditional media (Phillips, 2015). Online outlets are expected to be so fast that just taking the time to 
verify or weigh the importance of a story is a luxury (Le Cam \& Domingo, 2015). The online operations of some of the most serious media tend to be considerably more lax with rigor and even ethics, so that online media dare to publish stories that would not make the cut in their traditional outlet, be it a newspaper, a radio or a television news segment.

The turnover that has become consubstantial with digital outlets has created the need for a new form of reverse gatekeeping whereby it must be decided what story must be taken off the homepage to make room for new stories. The criteria for doing so can be a lack of interest as measured by clicks, or just a decrease in interest, or the fact that a story might have been found to be erroneous or biased. Gatekeeping used to be a one-way street; digital outlets have made it a two-way street where stories make it in, and at some point must make it out. The art of taking stories off digital outlets is mysterious, like traditional gatekeeping, but in a different way.

Likewise, gatekeeping must explain how news is removed from or altered in a news archive. While news was seen in the past as ephemeral - today's newspaper becomes tomorrow's fish wrap - news can now live on in news archives, ready to be accessed with a simple search. With this seeming permanency have come the occasional calls to delete or alter stories in the archive (English, 2009). This is not even to mention how web search engine operators, sometimes compelled by court orders, must process a dense flow of requests for un-referencing based on "the right to be forgotten" (Ambrose \& Ausloos, 2013, p. 1). Thus, gatekeeping must now account for both the publishing and the un-publishing of news.

The Agents of Gatekeeping. The agents of gatekeeping are also changing hands. Once largely a matter of news professionals, gatekeeping has been reappropriated by new actors on the news scene. From civil society organizations to citizen journalists and interest groups, the digital news scene is cluttered with various outlets providing content that is competing for attention with the more traditional news outlets (Powers, 2014). In the case of the Flint water crisis discussed above, one of the prominent investigative journalists who uncovered the story was no longer working for the local newspaper, but for the American Civil Liberties Union, an advocacy, non-profit organization (Clark, 2015).

Increasingly gatekeepers do not even have to shape information as news, but rather act as curators who merely navigate it and select and relay bits that can be easily repurposed. They are more gatewatchers than genuine gatekeepers 
(Bruns, 2005). These gatekeepers can also create alternative channels for news distribution. Politicians, preachers, activists, or anyone with a social following use social media, blogs, or other means to curate news for those who follow them (Thorson \& Wells, 2015). These agents are essential to explaining how some news does or does not end up making it to the public or to the public issue agenda.

In this same sense, the audience also functions as an important gatekeeping channel (Shoemaker \& Vos, 2009). Audience members email news stories and recipes and cat videos - to friends and family. They share stories via social media. The audience also has access to commenting sections and forums on news sites that allow them to communicate to fellow readers, but also with news organizations. These become portals for sharing information and shaping subsequent news coverage.

The mythology of the digital age has it that anyone can become anything, including a content producer or a gatekeeper. Here, it is too often speculated that because anyone is enabled to do things that used to be the monopoly of certain professions, then everyone is likely to do it in the foreseeable future. Yet not everyone wants to become his or her own news media curator and gatekeeper. In fact, it can be argued that as the background noise increases, people will want to rely increasing on professional gatekeepers in order to manage the overwhelming mass of content that pours on them continuously.

Context of Gatekeeping. The context of gatekeeping is changing along with the news industry, propelled by changing consumer habits and by economic disruptions (Kaye \& Quinn, 2010). The technologies made available to the news professionals, but also to their audiences, are bringing changes of such magnitude that major systemic changes are taking place quickly and almost organically, without anyone really calling the shots. Gatekeeping becomes just one among many factors that are inevitably affected by the transition, in connection with many other factors, all of which are swept along with the digital transition.

\section{Transition of Gatekeeping}

For some, the end of gatekeeping cannot come soon enough. The gatekeeping role is seen as an unhealthy form of paternalism. It is not just that audiences have new power in the digital media environment, but that audience power 
is to be celebrated and embraced. For others, normative judgments about the gatekeeping role are immaterial. Gatekeeping is simply seen as a phenomenon that is fading from the modern scene. Gatekeeping theory, it is believed, is fading with it.

It is tempting to see the many changes in the gatekeeping environment and to pronounce gatekeeping's demise. However, the most intellectually honest approach at the present is to see that gatekeeping theory must account for a world in transition. Gatewatching (Bruns, 2005) and way-finding (Pearson \& Kosicki, 2016) clearly describe aspects of the digital media environment that need not be reduced to gatekeeping. But the new digital universe has not yet arrived in its full manifestation, assuming it ever will. Thus, we are left to account for a news environment with both traditional and new purposes, natures, agents, temporalities, and contexts.

Theorizing about new environments comes with challenges. Theories are supposed to offer general principles. But, for social scientists, the goal is often nomothetic explanations; i.e., theories that explain a class of situations or events or that offer "abstract, general, or universal statements or laws" (Lehmann, 2010: 50). Most scholars would concede that theory does not need to speak to all times and all places, but what is the value of our theorizing if it captures only a snapshot in a seemingly constantly moving picture? Gatekeeping theory must be reformed; however, it will need to keep being reformed for the foreseeable future. 


\section{References}

Ambrose, M. L. \& Ausloos, J. (2013). The Right to be Forgotten across the Pond. Journal of Information Policy, 3: 1-23.

Anderson, C. W. (2013). Towards a Sociology of Computational and Algorithmic Journalism. New Media \& Society, 15(7), 1005-1021.

Bourdieu, P. (2005). The Political Field, the Social Science Field, and the Journalistic Field. In R. Benson \& E. Neveu (Eds.), Bourdieu and the journalistic field (pp. 29-47). Malden, MA: Polity.

Bruns, A. (2005). Gatewatching: Collaborative Online News Production. New York: P. Lang.

Bruns, A. (2011). Gatekeeping, Gatewatching, Real-time Feedback: New Challenges for Journalism. Brazilian Journalism Research, 7(11): 117-135.

Christians, C. G., Glasser, T. L., McQuail, D., Nordenstreng, K. \& White, R. A. (2009). Normative Theories of the Media: Journalism in Democratic Societies. Urbana: University of Illinois Press.

Clark, A. (2015). How an Investigative Journalist Helped Prove a City was Being Poisoned with Its Own Water. Retrieved from http://www.cjr.org/ united_states_project/flint_water_lead_curt_guyette_aclu_michigan.php.

Curran, J. (2010). Technology Foretold. In N. Fenton (ed.), New Media, Old News: Journalism and Democracy in the Digital Age (pp. 19-34). London: Sage.

English, K. (2009). The Longtail of News: To Unpublish or Not to Unpublish. Retrieved from http://c.ymcdn.com/sites/apme.site-ym.com/resource/ resmgr/online_journalism_credibility/a_suggested_script.pdf

Gieber, W. (1956). Across the Desk: A Study of 16 Telegraph Editors. Journalism Quarterly, 33: 423-432.

Harcup, T., \& O'Neill, D. (2001). What is News? Galtung and Ruge Revisited. Journalism Studies, 2(2): 261-280.

Heinderyckx, F. (2015). Gatekeeping Theory Redux. In T. P. Vos \& F. Heinderyckx (Eds.), Gatekeeping in Transition (pp. 253-267). New York: Routledge.

Hiner, J. (2016). Letter to the Editor: Local Media didn't Whiff on Flint Coverage. Retrieved from http://www.poynter.org/2016/letter-to-the-editornational-not-local-media-whiffed-on-flint-coverage/393583/. 
Janowitz, M. (1975). Professional Models in Journalism: The Gatekeeper and the Advocate. Journalism and Mass Communication Quarterly, 52(4): 618-626.

Kaye, J. \& Quinn, S. (2010). Funding Journalism in the Digital Age: Business Models, Strategies, Issues and Trends. New York: Peter Lang.

Le Cam, F. \& Domingo, D. (2015). The Tyranny of Immediacy: Gatekeeping Practices in French and Spanish Online Newsrooms. In T. P. Vos \& F. Heinderyckx (eds.), Gatekeeping in Transition (pp. 123-140). New York: Routledge.

Lehmann, H. (2010). The Dynamics of International Information Systems: Anatomy of a Grounded Theory Investigation. New York: Springer.

Lewin, K. (1951). Field Theory in Social Science: Selected Theoretical Papers. New York: Harper.

Moore, M. (2016). 10 Things They Won't Tell You about the Flint Water Tragedy, but I Will. Retrieved from http://www.huffingtonpost.com/michaelmoore/10-things-about-flint-water-tragedy_b_9132150.html?utm_hp_ ref=media\&ir=Media.

Negroponte, N. (1995). Being Digital (1st ed.). New York, NY: Vintage Books. Pearson, G. D. H. \& Kosicki, G. M. (2016). How Way-finding is Challenging Gatekeeping in the Digital Age. Journalism Studies, 1-19. doi:0.1080/14616 70X.2015.1123112

Phillips, A. (2015). Low-paid Piecework or Global Brands? In T. P. Vos \& F. Heinderyckx (eds.), Gatekeeping in Transition (pp. 65-81). New York: Routledge.

Pool, I. D. S. \& Shulman, I. (1959). Newsmen's Fantasies, Audiences, and Newswriting. Public Opinion Quarterly, 23: 145-158.

Powers, M. (2014). The Structural Organization of NGO Publicity Work: Explaining Divergent Publicity Strategies at Humanitarian and Human Rights Organizations. International Journal of Communication, 8(1): 90-107.

Reese, S. D. \& Ballinger, J. (2001). The Roots of a Sociology of News: Remembering Mr. Gates and Social Control in the Newsroom. Journalism \& Mass Communication Quarterly, 78(4): 641-658.

Schudson, M. (2012). The Sociology of News (2nd ed.). New York: W.W. Norton \& Company.

Shoemaker, P. J. (1991). Gatekeeping. Newbury Park: Sage Publications. 
Shoemaker, P. J. \& Vos, T. P. (2009). Gatekeeping Theory. New York: Routledge. Shoemaker, P. J. Vos, T. P. \& Reese, S. D. (2008). Journalists as Gatekeepers. In K. Wahl-Jorgensen \& T. Hanitzsch (eds.), The Handbook of Journalism Studies (pp. 73-87). New York: Routledge.

Starkman, D. (2014). The Watchdog that didn't Bark: The Financial Crisis and the Disappearance of Investigative Reporting. New York: Columbia University Press.

Stencel, M., Adair, B. \& Kamalakanthan, P. (2014). The Goat must be Fed: Why Digital Tools are Missing in Most Newsrooms. Duke Reporter's Lab. Retrieved from http://www.goatmustbefed.com/.

Sullivan, M. (2016). Should the Times have been a Tougher Watchdog in Flint? Retrieved from http://publiceditor.blogs.nytimes.com/2016/01/27/flintwater-margaret-sullivan-new-york-times-public-editor/?_r=0.

Tandoc, E. C. (2014). Journalism is Twerking? How Web analytics is Changing the Process of Gatekeeping. New Media \& Society, 16(4): 559-575.

Tandoc, E. C. (2015). Why Web Analytics Click: Factors Affecting the Ways Journalists Use Audience Metrics. Journalism Studies, 16(6): 782-799.

Tandoc, E. C. \& Vos, T. P. (2015). The Journalist is Marketing the News: Social Media in the Gatekeeping Process. Journalism Practice, 1-17. doi:10.1080/1 7512786.2015 .1087811

Thorson, K. \& Wells, C. (2015). How Gatekeeping still Matters: Understanding Media Effects in an Era of Curated Flows. In T. P. Vos \& F. Heinderyckx (eds.), Gatekeeping in Transition (pp. 25-44). New York: Routledge.

Vos, T. P. (2015). Revisiting Gatekeeping Theory in a Time of Transition. In T. P. Vos \& F. Heinderyckx (Eds.), Gatekeeping in Transition (pp. 3-24). New York: Routledge.

Warren, J. (2016). How the Media Blew Flint. Retrieved from http://www. poynter.org/2016/how-the-media-blew-flint/392662/.

White, D. M. (1950). The 'Gate Geeper:' A Case Study in the Selection of News. Journalism Quarterly, 27(4): 383-390. 
